\title{
Economic Impact of Applying High Strength Steels in Hydrogen Gas Pipelines
}

James R. Fekete ${ }^{a,}{ }^{,}$, Jeffrey W. Sowards ${ }^{a}$, Robert A. Amaro ${ }^{a, b}$

${ }^{a}$ Applied Chemicals and Materials Division, Material Measurement Laboratory, National Institute of Standards and Technology, 325 Broadway, Boulder, CO 80301

${ }^{\mathrm{b}}$ Mechanical Engineering Department, Colorado School of Mines, 1610 Illinois Street, Golden, CO 80401

"Corresponding Author (james.fekete@nist.gov)

Keywords: Steel, Hydrogen, Pipeline, Fatigue, Welding, Cost

\section{Abstract}

Steel pipelines will likely be employed extensively to transport gaseous hydrogen in support of a future clean energy economy. To date, a hydrogen-specific cost analysis of pipeline installation has not been produced. This paper performs several cost analyses in order to quantify cost differentials associated with hydrogen pipeline installation relative to (a) natural gas pipeline installation, (b) use of different pipe diameters and operating pressures, (c) use of X70 pipeline steel, and (d) use of X70 pipeline steel given a potential change in governing design code. The analysis concluded that there is a sizeable cost increase between natural gas and hydrogen pipeline installation (as much as $68 \%$, depending upon conditions). Furthermore, the analysis concludes that considerable cost savings can be realized if the hydrogen pipeline design/engineering code were modified to allow the use of X70 steel without penalty. Cost saving on the order of $32 \%$ may be realized, relative to use of X52 designed to the current code.

\section{Introduction}

The use of hydrogen for energy storage is one of many concepts being developed to increase usage of renewable energy sources. Hydrogen is a clean-burning fuel that can be used as a replacement for fossil fuels in internal combustion engines or in electrochemical fuel cells used to produce electricity. In both cases, the resultant byproduct is water vapor. Several major automakers, including Honda, Toyota, and Hyundai, are committed to producing commercial quantities of fuel cell vehicles in the 2015-2017 timeframe ${ }^{1}$. Although initially the hydrogen infrastructure will likely depend on over the road transportation in tank cars or tube trailers, ultimately the ability to move large quantities of hydrogen economically will depend on availability of pipelines. Pipelines are the most economical choice for transporting large quantities of fuels for long distances, with the most relevant example being that of natural gas. Pipeline delivery of hydrogen fuel is especially cost-effective in high-demand, densely populated markets ${ }^{2}$. The U.S. contains nearly 300,000 miles of interstate and intrastate transmission pipelines ${ }^{3}$. In contrast, the nation's network of hydrogen pipelines totals only 1500 miles. $^{4}$ Unlike natural gas, hydrogen is known to have a detrimental effect on the mechanical integrity of steel. When hydrogen is compressed within a pipeline, some of it adsorbs and subsequently absorbs into the wall of the pipe, which causes reductions in ductility and toughness. For this reason, the codes used for 
engineering of hydrogen pipelines have higher safety margins than those used for natural gas pipelines. While these margins have given hydrogen pipelines an excellent safety record, they also increase their cost. Although the cost of producing and distributing hydrogen is being reduced, more work is needed to make hydrogen cost-competitive with other fuels. This includes reducing the cost of pipeline transmission and distribution. For this reason, extensive ongoing research has been focused on developing a deeper understanding of hydrogen effects in steel, so that safety margins can be optimized and pipeline costs reduced without compromising safety and/or performance.

This paper focuses on the costs associated with hydrogen pipeline installation. A cursory review of the deleterious effects that hydrogen has upon steel is presented for background and analysis are presented to provide relative cost differential for hydrogen-service pipe with respect to natural gas-service pipe. Based on this knowledge we will present plausible opportunities for changes to engineering methods that could reduce costs without compromising safety. We will also identify areas where work is still needed to make the vision of lower cost pipelines a reality.

\section{Effect of hydrogen on steel properties relevant to pipeline engineering}

The embrittling effect of hydrogen on steel has been well known for decades, and mitigating this effect is important in many structural applications. As is true in most applications, the loading and environmental characteristics dictate the materials property requirements. Sufficient yield strength is key to ensure that the pipeline can withstand stresses caused by internal pressure. Fracture mechanics methods are used for pipeline design and structural integrity monitoring using parameters such as fracture toughness. Fracture toughness also determines a pipeline's resistance to third party damage, such as from impact from digging equipment. Fatigue crack growth resistance is especially important to gas pipelines. In addition to transporting gas, pipelines can be used as part of the storage strategy. By increasing and decreasing the pipeline pressure, gas can be stored and released as part of normal operation. In practice these pressurizing/depressurizing cycles take place once or twice a day, and the minimum pressure is generally $75-80 \%$ of the maximum pressure. In fatigue terminology, this is an application with a high load ratio value ( $R$ value $)^{1}$ and low frequency. The low frequency can exacerbate hydrogen effects, since the growing crack, when held open at the peak of the load cycle, provides an easy path for hydrogen absorption. Hydrogen can also have a deleterious effect on fatigue crack initiation and high cycle fatigue life, commonly characterized by stress-life (Wohler or S-N) curves ${ }^{5}$. However this duty cycle is more common in vehicle applications as opposed to pipeline service. Thus development of S-N data has not been a focus for pipeline applications to date.

In addition to these requirements for the base metal, steel alloys for pipelines must have adequate weldability to ensure that weld beads and accompanying heat affected zones have the correct levels of strength and toughness for the application. Many modern pipeline steels are manufactured using thermomechanical processing schemes such as controlled rolling, recrystallization controlled rolling and post rolling accelerated water cooling practices. These processes enable development of steels with high strength, but much lower alloy contents, resulting in lower carbon equivalents and resulting in improved

\footnotetext{
${ }^{1} \mathrm{R}$ value is the ratio of the minimum to the maximum load
} 
weldability ${ }^{6}$. The properties of welds are also important, as the microstructures of these materials are different than the base metal by virtue of the thermal cycling (and the melting/resolidification) they endure during the welding process. In addition, the violent nature of the weld process increases the likelihood of embedded defects such as inclusions or porosity. These defects can limit the performance of a welded pipe, and their impact on mechanical properties must be comprehended to ensure safe pipeline operation. Though outside of the scope of this paper, longitudinal welds, circumferential welds, and their respective heat-effected zones are also impacted adversely by gaseous hydrogen. These effects are not yet well understood and work is progressing at both NIST and Sandia National Laboratories to elucidate these effects. Corrosion resistance is also an important characteristic for pipeline service, but this topic is outside the scope of this paper.

\section{Cost Factors in Pipeline Engineering}

When pipeline cost estimates are needed for studying the cost of producing and delivering hydrogen, cost studies for natural gas pipelines are used as a starting point, based on data compiled by the Oil and Gas Journal. Construction costs are broken into four categories ${ }^{7}$ : Labor, Materials, Right of Way and Miscellaneous. Table I shows the average breakdown:

Table 1 - Cost Contributions for Natural Gas Pipeline Construction (from Reference 6)

\begin{tabular}{|l|l|}
\hline Labor & $45 \%$ \\
\hline Materials & $26 \%$ \\
\hline Right of Way & $22 \%$ \\
\hline Miscellaneous & $7 \%$ \\
\hline
\end{tabular}

As pipeline costs are generally quoted in dollars per unit length (e.g. $\$ /$ mile), material costs scale with both the diameter of the pipeline and the operating pressure. Labor costs are also impacted by material costs, especially by thickness, since thicker wall pipelines require more welding and heavier pipes may require more robust installation equipment. Right of way and miscellaneous costs are generally independent of material. However, right of way costs can vary by a factor of 7 based on where the pipeline is being installed ${ }^{8}$.

Changing the fuel being transmitted from natural gas to hydrogen affects the labor and materials cost components; however, a thorough treatment of these effects does not exist. The U. S. Department of Energy's Hydrogen and Fuel Cell Program has been working towards lowering the cost of hydrogen production, storage and distribution, and as part of their work have developed technoeconomic models of the hydrogen infrastructure. One of these models, the H2A Delivery Scenario Analysis Model V2.3 applies an across-the-board $10 \%$ increase in cost for hydrogen piping relative to natural gas piping, as documented in the User Guide for the model ${ }^{9}$. Although not stated specifically in the model documentation, the pipeline cost assumptions used in the model were based on the analysis in Reference 6 , and one can infer that the $10 \%$ cost premium was based on the impact of hydrogen on pipeline materials and labor costs discussed in that reference. Within the same timeframe as the development of the H2A models, the American Society of Mechanical Engineers' (ASME) B31 Pressure Piping Committee established a task group to develop a section of the code for hydrogen piping and pipelines, which was added to the code as Section B31.12 in $2008^{10}$. This new section utilized "materials 
performance factors" to make system design more conservative in the absence of substantial relevant test data on effects of hydrogen on pipeline materials ${ }^{11}$. These materials performance factors impose a cost penalty on hydrogen pipelines by requiring thickness increases for hydrogen pipelines at a given diameter and operating pressure relative to requirements for natural gas service. Due to lack of fatigue test data and lack of understanding of hydrogen-assisted fatigue response at the time of code creation, the material performance factors were based upon pipeline steel response to hydrogen under monotonic loading conditions. Specifically, the material performance factor requires an increase in minimum wall thickness for a given operating pressure and pipe diameter for all materials having a yield strength greater than $52 \mathrm{ksi}(358 \mathrm{MPa})$. The material performance factor can also be applied to materials having a yield strength less than $52 \mathrm{ksi}(358 \mathrm{MPa}$ ) if design operating pressures exceed 2200 psi (15 MPa). It was expected that as more relevant data became available that these design factors would be changed.

\section{Development of Improved Hydrogen Pipeline Codes}

As mentioned above, the ASME B31.12 code for hydrogen pipelines was implemented with very conservative requirements, with the intention of easing these requirements when hydrogen effects on steels in pipeline service were better understood. The need for understanding hydrogen effects on materials is important to many applications, including pipelines, and as a result, a comprehensive compilation of these results has been prepared by Sandia National Laboratory ${ }^{12}$, including information on carbon and low alloy steels used in pipeline applications. These results demonstrated a number of important effects, including higher crack growth rates with increasing hydrogen pressure and decreasing stress cycle frequency. This work made it clear that hydrogen effects on fatigue crack growth needed to be better understood before code changes could be made to reduce material usage.

With support from both the Departments of Energy and Transportation, the National Institute of Standards and Technology (NIST) embarked on a project to increase understanding of fatigue effects in pipeline steels, using a facility dedicated to developing fatigue data under conditions of hydrogen pressure and cycling frequency expected in hydrogen pipelines. Over the past several years data has been collected on several typical pipeline steel grades, and the resulting analyses have led to several important observations ${ }^{13}$ :

- Unlike ductility in a tension test, steels with higher yield strengths do not exhibit higher fatigue crack growth rates

- Microstructure appears to have an effect on fatigue crack growth, with fine microstructures resulting in higher growth rates

- The effect of pressure on fatigue crack growth also appears to be different for different microstructures

The data has been used to develop a model for hydrogen effects on pipeline steel fatigue crack growth ${ }^{14,15}$ which can predict pipeline lifetime based on assumed operating parameters. The existence of this data and model have provided the technical basis for proposed code changes that will enable pipeline engineers to reduce their materials usage and subsequent welding labor and materials costs when specifying a hydrogen pipeline. The next section of this paper will discuss the cost savings 
opportunities that could be realized if the code changes are implemented and used for pipeline engineering.

\section{Cost Study-Pipe}

Since the current cost modeling scheme provided in H2A Delivery Scenario Analysis Model V2.3 uses natural gas pipeline costs as a baseline, the following cost analysis will start by considering pipe thicknesses appropriate for natural gas service. The pipe thickness required for hydrogen service (all other variables held equal) is then determined. This set of baseline analyses provides a relative cost differential for hydrogen pipeline installation with respect to natural gas pipeline installation, based upon the current design and engineering codes used. Two further analyses are performed to determine the thickness of a higher specified minimum yield strength material required when designing to (a) the current hydrogen pipeline code, and (b) proposed changes to the current hydrogen pipeline code.

In order to establish the baseline, the American Society of Mechanical Engineers (ASME) B31.8-2012 Gas Transmission and Distribution Piping Systems code was used to determine the required pipe thicknesses for 12", 24" and 36" (304.8, 609.6 and 914.4mm) diameter pipes for 1000 psi (6.89 MPa) and 1500 psi (10.34 MPa) natural gas operating pressures. The engineering code B31.8 references the ASME Boiler and Pressure Vessel (BPV) code Article KD-30 and the American Petroleum Institute (API) fitness for service (FFS) API 579-1/ASME FFS-1 2007 as part of the overall engineering analysis. The diameters chosen match those used in hydrogen service currently as well as the potential size of future pipelines. Per conversations with ASME B31.12 committee members, the current maximum hydrogen gas pipeline operating pressure is $1000 \mathrm{psi}(6.89 \mathrm{MPa})$, while $1500 \mathrm{psi}(10.34 \mathrm{MPa})$ has been set as a future operating pressure goal. Furthermore, it was conveyed during these discussions that hydrogen pipeline operators require pipelines having a minimum of schedule 20 wall thickness in order to ensure sufficient robustness to resist accidental (e.g. ${ }^{\text {rd }}$ party) damage. In this context "schedule" refers to the thickness specification used in pipe materials and is a function of the nominal pipe diameter. Finally, these conversations also informed the authors that high frequency electric resistance welded (ERW) pipes are preferred for hydrogen service, regardless of pipe nominal diameter and thickness. As such ERW longitudinal seams were assumed in all analysis. API $5 \mathrm{~L} \mathrm{X52} \mathrm{(X52)} \mathrm{was} \mathrm{chosen} \mathrm{as} \mathrm{the} \mathrm{baseline} \mathrm{material,}$ as that is the material with the largest specified minimum yield strength (SMYS) allowed for hydrogen service without a thickness penalty assessed via the material performance factors set forth in ASME B31.12-2008. The results of the baseline natural gas analysis are provided in Table 2. The analysis was performed using the design factor for Location Class 1 , Division 2 equal to $F=0.72^{16}$. Numerical values shown in Tables 2 through 8 are converted to the SI scale in Appendix B.

Table 2: Baseline (X52) Natural Gas Pipe Thickness Analysis (ASME B31.8-2012)

\begin{tabular}{|l|c|c|c|}
\hline \multirow{2}{*}{ Operating } & \multicolumn{3}{|c|}{ Pipe Diameter } \\
\cline { 2 - 4 } Pressure & $12 "$ & $24 "$ & $36 "$ \\
\hline $1000 \mathrm{psi}$ & Required & 2hickness- schedule (inches) \\
\hline $1500 \mathrm{psi}$ & $20(0.25)$ & $20(0.375)$ & $20(0.50)$ \\
\hline
\end{tabular}


Further analysis was performed using ASME B31.12-2008 (Hydrogen Piping and Pipelines) in conjunction with ASME BPV Article KD-30, KD-10, and API 579-1/ASME FFS-1 2007 to determine the required pipe thicknesses for 12", 24" and 36" (304.8, 609.6 and 914.4mm) diameter pipes for 1000 psi (6.89 MPa) and 1500 psi (10.34 MPa) gaseous hydrogen operating pressures. The baseline hydrogen gas analysis uses X52 as the pipeline material, for the same reasons stated above. The analysis was performed using the design factor, $F$, for Location Class 1 , Division 2 equal to $F=0.5^{10}$. Results of the baseline hydrogen gas analysis are provided in Table 3.

Table 3: Baseline (X52) Hydrogen Gas Pipe Thickness Analysis (ASME B31.12-2008)

\begin{tabular}{|l|c|c|c|}
\hline \multirow{2}{*}{$\begin{array}{l}\text { Operating } \\
\text { Pressure }\end{array}$} & \multicolumn{3}{|c|}{ Pipe Diameter } \\
\cline { 2 - 4 } & Required Thickness- schedule (inches) \\
\hline $1000 \mathrm{psi}$ & $20(0.25)$ & $30(0.562)$ & $40(0.75)$ \\
\hline $1500 \mathrm{psi}$ & STD $(0.375)$ & $60(0.969)$ & N/A \\
\hline
\end{tabular}

The results indicate that at $1000 \mathrm{psi}(6.89 \mathrm{MPa})$, a 12 " $(304.8 \mathrm{~mm})$ diameter pipe would have the same wall thickness if designed for natural gas or hydrogen service. Conversely, a 24" $(609.6 \mathrm{~mm})$ pipe would need to have schedule 30 minimum wall thickness when placed in hydrogen service, whereas the analysis for natural gas service only requires schedule 20 wall thickness. Thus, for 24 " $(609.6 \mathrm{~mm})$ diameter pipe under the given conditions, a hydrogen pipeline requires $48 \%$ more material relative to natural gas pipeline. As steel is sold on a dollar/pound basis, the results indicate a $48 \%$ increase in price for the pipe material alone. Whenever the analysis requires a pipe thickness greater than that available for a given diameter, "N/A" was used in Table 3 and all subsequent Tables. The baseline hydrogen pipeline analysis indicates that a 36" $(914.4 \mathrm{~mm})$ diameter pipe is not available with sufficient thickness to be used at $1500 \mathrm{psi}$ (10.34 MPa) operating pressure.

The current ASME B31.12 allows for use of materials having SMYS higher than $358.2 \mathrm{MPa}(52,000 \mathrm{ksi})$ as long as the specified material performance factors (penalties) are used in the design. However, a report by Briottet et al. suggested that employing higher strength steels (X80) has up to $40 \%$ cost incentive over using lower grade pipe, even with higher hydrogen embrittlement susceptibility ${ }^{17}$. Therefore, further analysis was performed using an API $5 L X 70(X 70)$ grade pipeline steel to determine the resultant effects upon required pipe thickness, and therefore price. The results of this analysis are provided in Table 4.

Table 4: Hydrogen Gas Pipe Thickness Analysis for X70 (ASME B31.12-2008)

\begin{tabular}{|l|c|c|c|}
\hline \multirow{2}{*}{$\begin{array}{l}\text { Operating } \\
\text { Pressure }\end{array}$} & \multicolumn{3}{|c|}{ Pipe Diameter } \\
\cline { 2 - 4 } & Required & 24" & $36 "$ \\
\hline $1000 \mathrm{psi}$ & $30(0.330)$ & $30(0.562)$ & N/A \\
\hline $1500 \mathrm{psi}$ & $40(0.406)$ & $60(0.969)$ & N/A \\
\hline
\end{tabular}


Per the current ASME B31.12 code, use of X70 will result in a thickness increase for 12" $(304.8 \mathrm{~mm})$ diameter pipes and no change for $24 "(609.6 \mathrm{~mm})$ diameter pipes when compared to X52, for the operating pressures analyzed. Furthermore, pipe is not available with sufficient thickness when designing for hydrogen service using a 36" $(914.4 \mathrm{~mm})$ diameter pipe at either operating pressure. As the vast majority of the hydrogen-specific pipelines in use today are in the range of 12 " $(304.8 \mathrm{~mm})$ diameter, use of X70 would result in an increase in material costs over use of X52, given the current B31.12 design code and current hydrogen capacity requirements.

Recent work performed at NIST and Sandia National Laboratories have indicated that the material performance factors penalizing the use of any material having a SMYS over that of X52 are likely too conservative. Specifically, research has shown that fatigue crack growth rate of $X 52, X 70$ and $X 80$ all fall within each other's experimental scatter bands, for the same test conditions. As a result the ASME B31.12 committee is drafting new code language which removes the material performance factor design penalty assessed to X70 pipeline steel. The preceding analysis was repeated using the proposed code modification and the results are provided in Table 5.

Table 5: Hydrogen Gas Pipe Thickness Analysis for X70 (ASME B31.12-Proposed)

\begin{tabular}{|l|ccc|}
\hline \multirow{2}{*}{$\begin{array}{l}\text { Operating } \\
\text { Pressure }\end{array}$} & \multicolumn{3}{|c|}{ Pipe Diameter } \\
\cline { 2 - 4 } & Required Thickness- schedule (inches) \\
\hline $1000 \mathrm{psi}$ & $20(0.25)$ & $20(0.375)$ & $20(0.312)$ \\
\hline $1500 \mathrm{psi}$ & $20(0.25)$ & $30(0.556)$ & $40(0.75)$ \\
\hline
\end{tabular}

The analysis indicates that once the B31.12 code is modified, use of X70 pipes in gaseous hydrogen service will result in reduced pipe thickness, and therefore weight and cost savings when compared to X52 at all conditions analyzed except 12" diameter operating at $1000 \mathrm{psi}(6.89 \mathrm{MPa}$ ) hydrogen pressure. Specifically, implementing the code modification would allow an X70, 24" $(609.6 \mathrm{~mm})$ diameter schedule 20 pipe operating at $1000 \mathrm{psi}(6.89 \mathrm{MPa})$ hydrogen pressure, whereas the current code results in the use of X52, 24" diameter $(609.6 \mathrm{~mm})$ schedule 30 pipe. This would result in a $33 \%$ weight savings and a considerable cost savings. Market research shows that the price premium for X70 over X52 is approximately $10 \%$, thus the cost savings in this example would be over $26 \%$.

A welding cost model was developed to evaluate the influence of welding variables on the economics associated with pipeline installation (labor in Table 1). The assumptions that were made in the welding cost model are as follows:

- The heavy equipment required for digging trenches and dropping pipe are the same regardless of pipe dimensions. Therefore, installation costs not related to welding are fixed.

- Pipe tolerances are such that no special weld preparation is required.

- Non-destructive evaluation (NDE) costs and weld repair costs are ignored in this analysis. It is expected that larger diameter and thicker-walled pipe would incur higher NDE costs. Likewise the higher weld volume might increase weld repair rates with a fixed repair frequency required. 
As in the pipe material cost analysis above, $\mathrm{X} 52$ and $\mathrm{X} 70$ are considered here, as are the same two hydrogen transport pressures (1000 psi and $1500 \mathrm{psi}, 6.89 \mathrm{MPa}$ and $10.34 \mathrm{MPa}$ ). Based upon the pipe material cost analysis, the following two scenarios are used for the labor and install analysis. The two scenarios were chosen in order to compare use of the current B31.12 code for X52 pipeline installation (Table 3, least expensive current option) and the use of the potential B31.12 modified code for X70 pipe (Table 5, least expensive future option). The complete analysis is shown in Appendix A of this report.

The two cost analyses (material and welding) can be combined in order to draw conclusions regarding total pipe installation cost differentials. First, one can make a comparison of cost differences between pipes engineered for natural gas (ASME B31.8-2012) and hydrogen (ASME B31.12-2008). Based on the engineering requirements of these codes, the cost differential for $X 52$ pipeline in hydrogen service is provided in Table 6.

Table 6: Cost increase for X52 pipes engineered for hydrogen service (B31.12) relative to natural gas service (B31.8)

\begin{tabular}{|l|c|cc|}
\hline \multirow{2}{*}{$\begin{array}{l}\text { Operating } \\
\text { Pressure }\end{array}$} & \multicolumn{3}{|c|}{ Pipe Diameter } \\
\cline { 2 - 4 } & \multicolumn{3}{|c|}{ Total Cost Differential/Mile } \\
\hline $1000 \mathrm{psi}$ & $0 \%$ & $42 \%$ & $44 \%$ \\
\hline $1500 \mathrm{psi}$ & $11 \%$ & $68 \%$ & N/A \\
\hline
\end{tabular}

The results in Table 6 clearly indicate that based on the current codes hydrogen pipeline installations have significantly higher cost, for the given conditions studied.

Table 7 describes an analysis that uses the existing ASME B31.12 engineering code, as this represents the current reality of hydrogen pipeline design. Using the X52, 12 inch $(304.8 \mathrm{~mm})$ pipeline operating at 1000 psi (6.89 MPa) hydrogen as a baseline, the following cost increase can be expected when installing X52 pipelines at either (a) higher operating pressure, or (b) larger diameters.

Table 7: Cost impact of increasing diameter and/or operating pressure of X52 pipe for hydrogen service (12" (304.8mm), 1000 psi (6.89 MPa) baseline)

\begin{tabular}{|l|ccc|}
\hline \multirow{2}{*}{$\begin{array}{l}\text { Operating } \\
\text { Pressure }\end{array}$} & \multicolumn{3}{|c|}{ Pipe Diameter } \\
\cline { 2 - 4 } & $12^{\prime \prime}$ & $24 "$ & $36 "$ \\
\hline $1000 \mathrm{psi}$ & \multicolumn{2}{|c|}{ Total Cost Differential/Mile } \\
\hline $1500 \mathrm{psi}$ & - & $214 \%$ & $540 \%$ \\
\hline
\end{tabular}

One readily sees a drastic increase in installation costs once either the operating pressure or the pipe diameter are increased, as would be expected. Of interest then, is the cost savings that could be realized given a modification of the B31.12 code which would allow the use of $X 70$ without penalty. The results of the cost differential analysis, for the same operating conditions, when $X 70$ pipe is used (modified B31.12), as opposed to X52 (current B31.12) are provided in Table 8. A 10\% surcharge on raw material has been added to the results to account for alloy cost differential. 
Table 8: Cost impact of replacing X52 with X70 for hydrogen service - all other variables equal

\begin{tabular}{|l|ccc|}
\hline \multirow{2}{*}{$\begin{array}{l}\text { Operating } \\
\text { Pressure }\end{array}$} & \multicolumn{3}{|c|}{ Pipe Diameter } \\
\cline { 2 - 4 } & \multicolumn{3}{|c|}{ Total Cost Differential/Mile } \\
\hline $1000 \mathrm{psi}$ & $-2 \%$ & $-24 \%$ & $-25 \%$ \\
\hline $1500 \mathrm{psi}$ & $-19 \%$ & $-31 \%$ & $\mathrm{~N} / \mathrm{A}$ \\
\hline
\end{tabular}

Table 8 indicates that across all variables the $X 70$ pipe provides a decrease in cost per mile of installed pipe. The greatest savings in using $X 70$ (31\%) can be seen when one installs a 24 inch $(609.6 \mathrm{~mm})$ pipe to transport 1500 psi (10.34 MPa) gaseous hydrogen. Note that an X52 pipe is not made with sufficient wall thickness to support 36 inch $(914.4 \mathrm{~mm})$ diameter at $1500 \mathrm{psi}(10.34 \mathrm{MPa})$ operating conditions. As such a comparison between the two materials could not be made. Having said that, utilizing X70 provides the previously unavailable opportunity to use 36 inch $(914.4 \mathrm{~mm})$ diameter pipe to transport hydrogen at 1500 psi (10.34 MPa).

\section{$\underline{6 . \text { Conclusions }}$}

Pipelines are likely the most economical way to transport gaseous hydrogen. Hydrogen has a deleterious effect upon critical mechanical properties of steel. As such hydrogen-specific engineering codes exist to aid engineers in hydrogen pipeline design. This work performed several analyses to (a) determine the cost differential between natural gas and hydrogen pipeline installation, (b) determine the cost differential associated with either increasing the pipeline diameter or operating pressure, and (c) the cost differential associated with a code modification enabling the unhindered use of X70.

The following conclusions can be drawn from this paper:

- A considerable cost increase is associated with the installation of hydrogen-specific pipelines, relative to the cost associated with natural gas pipelines. The cost increase can be as large as $68 \%$, depending upon pipe diameter and operating pressure.

- Regardless of the assumptions used, 12 inch $(304.8 \mathrm{~mm})$ schedule 20 pipe can transport 1000 psi (6.89 MPa) hydrogen or natural gas. This condition should be seen as a baseline for any subsequent analysis.

- Use of the current B31.12 code to engineer X70 pipeline steel results in a cost-prohibitive pipeline, as indicated by the required thicknesses provided in Table 4.

- Considerable cost savings can be realized by modifying the ASME B31.12 Hydrogen Piping and Pipeline Code to remove the Material Performance Factors used to penalize API X70 pipeline steel. A reduction of $31 \%$ is realized when using 24 inch $(609.6 \mathrm{~mm}) \times 70$ pipe to transport 1500 psi (10.34 MPa) gaseous hydrogen, relative to the use of X52. Furthermore, modification of the current B31.12 code would enable use of 36 inch $(914.4 \mathrm{~mm})$ X70 pipe to transport 1500 psi (10.34 MPa) hydrogen gas. This diameter-pressure combination is not possible when using the current code. Modification of the code and use of this condition provides the opportunity to 
either transport a larger volume of hydrogen or provide a larger volume of storage within the pipeline system.

\section{$\underline{\text { Acknowledgements }}$}

The authors wish to acknowledge Ms. Neha Rustagi, an ORISE Fellow (funded by the Oak Ridge Institute for Science and Education) currently working at the U. S. Department of Energy, for her critical review of this manuscript. This work was partially supported by the U. S. Department of Transportation, Pipeline and Hazardous Material Safety Agency under Interagency Agreement No. DTPH56-13-X-000019 
APPENDIX A: Weld Cost Study- Labor and Installation

\section{Welding Consumables}

We assume that all welding is performed with the shielded metal arc welding (SMAW) process in the vertical down progression. This process is commonly employed for cross country pipe welding and has high deposition rates due to relatively high welding currents. This process is highly portable as it does not require a mechanical wire feeding mechanism nor does it need external shielding gas. Other welding processes are used in pipe welding (including flux cored arc welding and gas tungsten arc welding), although the SMAW process has high field usage due to its portability.

Selection of proper welding consumables depends on the strength of the parent pipe material. Pipe welding procedures often call for filler metals with undermatched mechanical properties for root pass welding, and matching or overmatching mechanical properties for fill and cap passes. For example, E6010 (60 ksi (413.7 MPa) minimum tensile strength) is commonly used for joining X52 pipe sections and E8010-G (80 ksi (551.6 MPa) minimum tensile strength) is commonly used for joining X70. Preheat and control of welding interpass temperature may or may not be performed depending on the qualified weld procedure for either grade X52 or X70. Here we assume that conditions are such that no preheat is performed nor is an interpass temperature maintained. Such procedure modifications would have some influence on overhead costs and operator factor (described below). Overhead cost would likely increase somewhat due to additional gas and torch costs. Operator factor would decrease as welder time is spent on tasks other than welding.

Filler Metal Density. The density of steel is approximately $0.284 \mathrm{lb} / \mathrm{in}^{3}$ and does not vary significantly among the different steel welding consumables since alloying levels are quite low. Therefore, this value was assumed to be a constant in the calculations.

Filler Metal Cost. Market research was performed to determine cost estimates of E6010 and E8010 electrodes. Over $50 \mathrm{E} 6010$ and E8010 consumables produced by four different manufacturers were priced accordingly. The cost of the E8010 filler metal increases over the E6010 presumably due to minor alloying additions and differing flux coating composition. Results of the welding consumable market research are shown in Table A.1. We assume average welding consumable prices in the cost model.

Table A.1: Comparison of welding consumable costs.

\begin{tabular}{|l|l|l|}
\hline Cost $(\$ / \mathrm{lb})$ & $\mathrm{E} 6010$ & $\mathrm{E} 8010$ \\
\hline Minimum & $\$ 2.73$ & $\$ 3.20$ \\
\hline Maximum & $\$ 3.75$ & $\$ 4.41$ \\
\hline Average & $\$ 3.19 \pm \$ 0.26$ & $\$ 3.89 \pm \$ 0.32$ \\
\hline Sample size, $N=51$ & \\
\hline
\end{tabular}

Gas Usage. The SMAW process is self-shielded, i.e., no external shielding gas is required to protect the weld pool from atmospheric contamination. The E6010 and E8010 electrodes have cellulosic coatings that decompose into gases and shield the welding arc and weld pool, precluding atmospheric contamination. Therefore, gas usage is not included in the cost model. 
Power Cost. Electrical power is required for arc welding processes. This power may be supplied by adjacent transmission lines or portable generators in field welding. Gasoline or diesel generators would have an associated fuel cost. We assume an average power cost of $\$ 0.15 / \mathrm{kW}-\mathrm{hr}$.

\section{Labor Costs \& Human Factor}

Labor Rate. Welder labor rates vary widely by industry and locality. The Bureau of Labor Statistics publishes labor profiles for weld professions.

(Reference: http://www.bls.gov/oes/current/naics4_486200.htm) Welders working in the "Pipeline Transportation of Natural Gas" industry receive an average hourly wage of \$23.19 per hour. We assume this average wage in our calculations.

Overhead Rate. Overhead rate varies depending on the size of the welding service provider and include operating and maintenance costs for capital expenditures. For the purpose of weld cost analysis, overhead rate is often assumed to be equivalent to Labor Rate. In line with this assumption, a large North American producer of welding consumables suggests using an average combined overhead-labor rate of $\$ 45$ per hour for cost calculations.

(Reference:

http://www.esab.ca/shared/documents/litdownloads/crcbooklet/files/assets/seo/page12.html). The suggested combined rate is just under twice the average labor rate defined above by the Bureau of Labor Statistics. We assume overhead rate is equal to welder labor rate.

Operator Factor. The operator factor describes the percentage of a welder's work shift that is spent welding, i.e., the fraction that the arc is "on". A welder operating the SMAW process may have an operator factor within the range of $5 \%$ to $30 \%$

(Reference: Economics of Welding and Cutting, American Welding Society, 2001). The factor depends on e.g., surrounding conditions, fixturing, and welder experience. To demonstrate how this value is used: a welder would actually be depositing metal 1.6 hours out of an 8-hour shift with an operator factor of $20 \%(20 \% * 8 \mathrm{hr}=1.6 \mathrm{hr})$. We assume an operator factor of $20 \%$ in these calculations.

\section{Welding Process}

Average Current. SMAW pipe welding is typically performed with a constant current power supply in the DC electrode positive (DCEP) mode to allow for deeper penetration. The welding current, which is set by the welder, may depend on electrode diameter, welder skill level, and pipe thickness. Higher welding current increases the deposition rate, which in turn enhances productivity. Welding current for thin-wall piping (defined here as pipe having thicknesses less than $0.25^{\prime \prime}$ ) is typically lower than current used for thick-wall (pipes having thicknesses over $0.25^{\prime \prime}$ ). Welding current for the root pass of thin-wall and thick-wall pipe may be on the order of $100 \mathrm{amps}$ and $140 \mathrm{amps}$, respectively. Fill and cap passes use higher currents and are typically on the order of 130 amps and 190 amps for thin and thick wall pipe, respectively. Most welding procedures for pipelines specify different levels of welding current depending on the pass location (e.g., root, fill, cap). For the cost analysis, we assume a constant 120 amps average welding current for the 0.25 -inch and thinner pipe and a constant 180 amps average welding current for pipe thicknesses greater than 0.25 inches.

Average Voltage. The welder controls arc voltage as they vary the height between the electrode tip and the work piece. This is done to achieve ideal electrode operating characteristics. Voltage has only a small effect on deposition characteristics but does have an effect on power consumption. At the 
welding current ranges listed above, E6010 and E8010 electrodes operate in a voltage range of approximately $22 \mathrm{~V}$ to $28 \mathrm{~V}$. We assume a constant voltage of $24 \mathrm{~V}$ for the cost model.

Deposition Efficiency. The electrode deposition efficiency is the ratio of the mass of deposited metal in the joint to the total mass of the electrode. SMAW consumables always have a stub remaining at the end of the weld that must be discarded. We assume that the stub is 2 inches in length, which accounts for a loss of $14 \%$ of a 14 inch electrode. Some of the electrode is also lost due to spatter and fume. This accounts for another $\sim 20 \%$ reduction in metal deposited in the weld. As a result of these losses, SMAW electrode efficiency typically varies between $65 \%$ and $75 \%$ depending on electrode diameter and current. We assume a deposition efficiency of $70 \%$.

Deposition Rate. The deposition rate describes the mass of metal deposited into the weld per unit time (e.g., lb/hr). Welding current has the greatest effect on the deposition rate when employing the SMAW process. In the cost model, we developed a regression $\left(R^{2}=0.918\right)$ from handbook sources (Reference: Welding Handbook vol. 2, Eight Edition, American Welding Society, 1995) that relates welding current, I (amps) and electrode deposition rate. The equation is shown in Table A.2.

Fill Volume. The typical joint configuration of a pipe weld is a "penny gap, penny land" where the Vgroove is beveled to 60 degrees and separated by a root opening of a penny width ( 0.0625 inch) with a 0.0625 inch land (Figure A.1). The volume of deposited weld metal necessary to fill this joint configuration depends on pipe diameter and the thickness of the pipe. Larger pipe thicknesses require more weld deposit to complete the weld. Weld reinforcement will increase somewhat with pipe thickness as well. A polynomial regression was used to model the amount of filler metal required to fill this joint geometry as pipe thickness increases. A regression $\left(R^{2}=0.996\right)$ was developed using fillvolume data from AWS D1.1/D1.1M:2006, Structural Welding Code - Steel, American Welding Society, 2006 and several consumable manufacturer product literature sources that describe the volume per unit length, $V\left(\mathrm{in}^{3} / \mathrm{ft}\right.$ ) of metal required to fill a $V$-groove joint of thickness, $T$ (in). An average pipe circumference, $C(\mathrm{ft})$ is taken at the mid-thickness of the pipe wall (i.e., $T / 2$ ). The product of the circumference and the volume per unit length gives the necessary weld deposit volume $\left(\mathrm{in}^{3}\right), D V$ to complete the weld. Fill equations are listed in Table A.2.
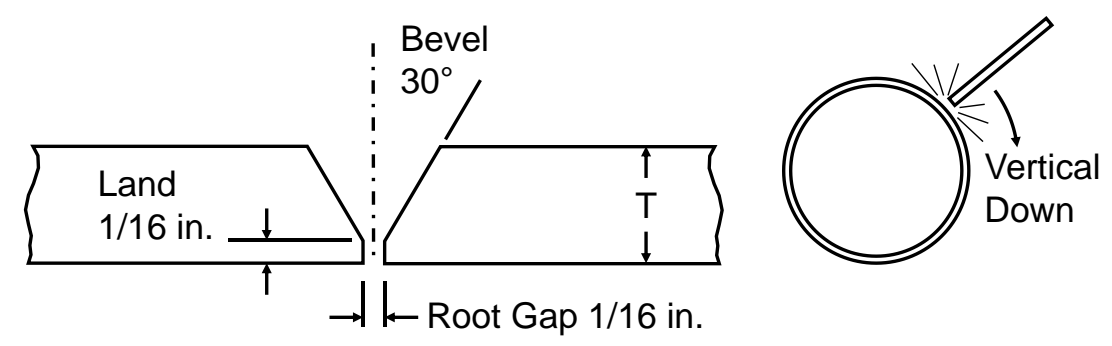

Figure A.1 : Typical butt weld configuration for vertical down pipe welding in the field where the dimension, $T$ is the pipe wall thickness.

\section{Cost Analysis}

The cost parameters described above and the relevant equations used to perform the cost analysis are shown in Table A.2. Rationale was provided above for selection of nominal values for the model inputs. 
These equations were solved using the nominal values to develop baseline costs of completing a girth weld joint for the conditions described in Table A.2.

Table A.2: Equations used for weld cost analysis.

\begin{tabular}{|c|c|c|}
\hline Description & Equation & Unit \\
\hline Deposition rate & $D R(I)=0.0267 * I-0.8736 \quad\left(R^{2}=0.918\right)$ & $\mathrm{lb} / \mathrm{hr}$ \\
\hline Joint fill volume & $V(T)=9.3084 * T^{2}+1.3502 * T+0.152 \quad\left(\mathrm{R}^{2}=0.996\right)$ & $\mathrm{in}^{3} / \mathrm{ft}$ \\
\hline Weld deposit volume & $D V=C^{*} V(T)$ & $\mathrm{in}^{3}$ \\
\hline Weld deposit mass & $M_{\mathrm{d}}=D V^{*} \rho$ & $\mathrm{Ib}$ \\
\hline Weld time & $t_{\text {weld }}=M_{\mathrm{d}} / D R(I)$ & $\mathrm{hr}$ \\
\hline Labor time & $t_{\text {labor }}=t_{\text {weld }} / \mathrm{OF}$ & $\mathrm{hr}$ \\
\hline Power cost & $P_{\text {cost }}=E^{*} / * t_{\text {weld }} * P P^{*}(1 / 1000)$ & \$/joint \\
\hline Deposited metal cost & $D M_{\text {cost }}=M_{\mathrm{d}} * F M C$ & \$/joint \\
\hline Labor cost & $L_{\text {cost }}=t_{\text {labor }} * L$ & \$/joint \\
\hline Overhead cost & $O_{\text {cost }}=t_{\text {labor }} * O R$ & \$/joint \\
\hline Total cost & $T_{\text {cost }}=P_{\text {cost }}+D M_{\text {cost }}+L_{\text {cost }}+O_{\text {cost }}$ & \$/joint \\
\hline $\begin{array}{l}\text { Definition of variables } \\
I=\text { Welding current (ar } \\
T=\text { pipe thickness (in) } \\
C=\text { pipe circumferenc } \\
\rho=\text { steel density }, 0.28 \\
O F=\text { operator factor }( \\
E=\text { welding voltage }(\mathrm{v} \\
P P=\text { power price }(\$ / \mathrm{k}) \\
F M C=\text { filler metal cost } \\
L R=\text { labor rate }(\$ / \mathrm{hr}) \\
O R=\text { overhead } \mathrm{rate}(\$\end{array}$ & $\begin{array}{l}T / 2(\mathrm{ft}) \\
/ \mathrm{in}^{3}\end{array}$ & \\
\hline
\end{tabular}

The costs to complete a single girth weld for each material condition were computed using the nominal values described above. The numerical results of the calculations are shown in Table A.3 and the relative magnitude of each cost is indicated by the horizontal (shaded) bars. The small diameter, thinwalled pipe has the lowest welding cost, whereas the larger diameter, thick-walled pipe has higher welding cost, as expected. The most expensive (\$/joint) weld to produce is the 24 inch diameter X52 pipe for 1500 psi service. The heavy wall thickness (schedule 60) drives up the cost as the weld deposit volume is highest for this particular pipe condition. Note that volume required to fill the joint is proportional to the thickness squared (See section on fill volume). Also note that welding costs do not vary significantly among the different strength pipe materials with a fixed diameter and thickness combination.

Table A.3: Girth weld cost per joint for several pipeline conditions. 


\begin{tabular}{|c|c|c|c|c|}
\hline Pipeline Condition & X52 (1,000 psi) & X52 (1,500 psi) & X70 (1,000 psi) & X70 (1,500 psi) \\
\hline 12 in. Schedule 20 & $\$ 105$ & & $\$ 106$ & $\$ 106$ \\
\hline $12 \mathrm{in.}$ Schedule STD & & \$117 & & \\
\hline 24 in. Schedule 20 & & & $\$ 225$ & \\
\hline 24 in. Schedule 30 & $\$ 433$ & & & $\$ 439$ \\
\hline 24 in. Schedule 60 & & $\$ 1,179$ & & \\
\hline 36 in. Schedule 20 & & & $\$ 542$ & \\
\hline 36 in. Schedule 40 & $\$ 1,080$ & & & $\$ 1,097$ \\
\hline
\end{tabular}

The pie charts shown in Figure A.2 reveal cost breakdown, by percentage, of the four computed welding costs for thin-wall and thick-wall pipe. Labor and overhead make up over $90 \%$ of welding costs irrespective of pipe wall thickness. The cost distribution varies slightly when switching from a thin-wall to a thick wall-pipe as the higher welding current used for joining thick-wall pipe increases weld metal deposition rate. This effectively decreases the relative costs of labor and overhead since welds take less time to produce. The filler metal makes up over $4 \%$ of costs for thin-wall pipe and over $7 \%$ of costs for thick-wall pipe. Power consumption is the lowest cost ( $0.3 \%$ or less) regardless of pipe-wall thickness.

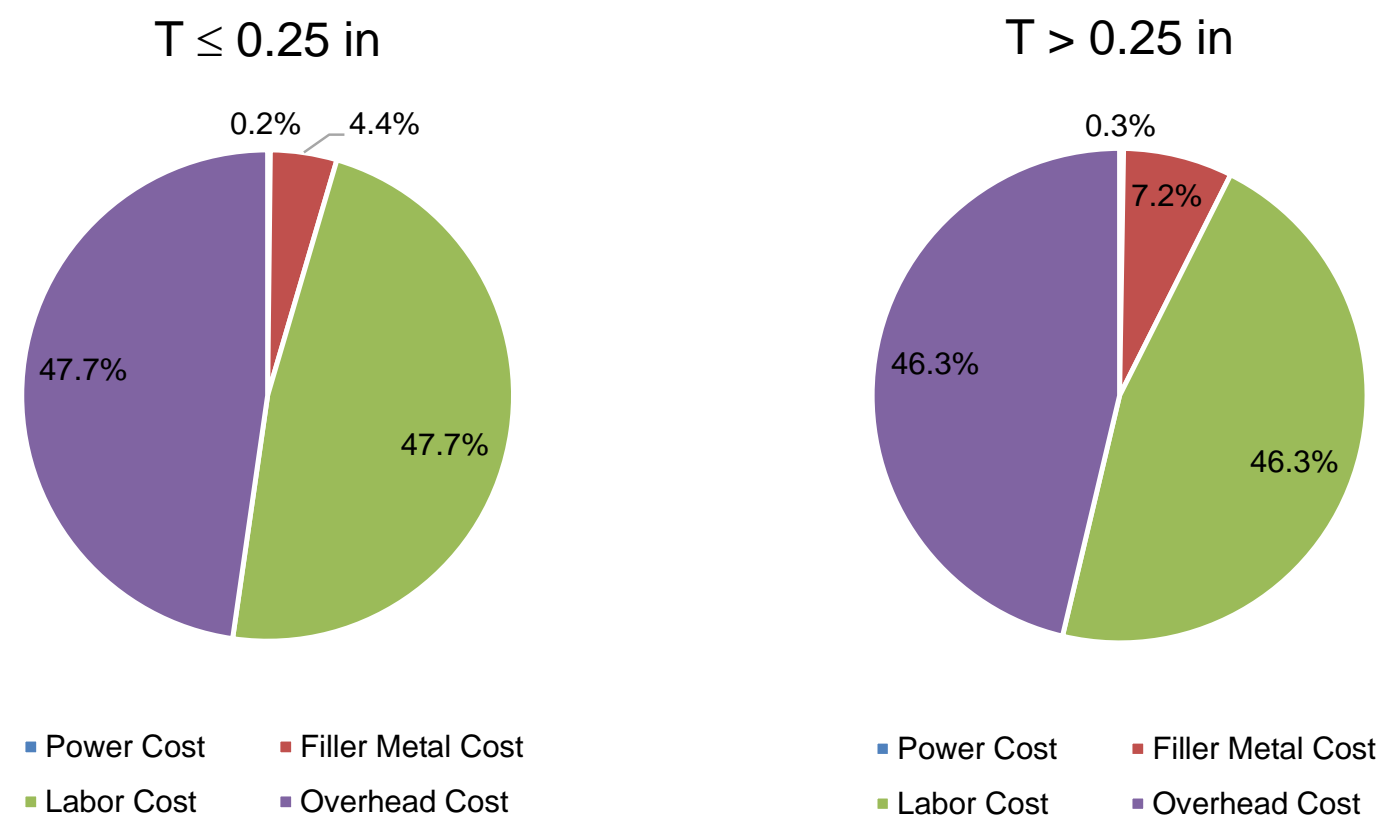

Figure A.2: Breakdown of welding costs for thin-wall ( $T \leq 0.25 \mathrm{in}$ ) and thick-wall pipe ( $T>0.25 \mathrm{in})$.

A useful value for comparison is the welding cost per mile. This cost depends greatly on the length of the pipe sections being welded as shorter pipe sections require more welding to complete a mile of installation. Commercially available pipe sections often vary between approximately $20 \mathrm{ft}$ and $40 \mathrm{ft}$ in length and are sold in $10 \mathrm{ft}$ increments within that range. The number of joints in a mile are determined for the three lengths of pipe within this length range, and the resulting welding-cost per mile is shown in Figure A.3 for two API 5L pipeline grades intended for 1500 psi (10.34 MPa) pressure. The figure illustrates that when the pipe section length is doubled, the welding cost decreases by a factor of 2 . 
Note also that the weld cost per mile for the 12 inch diameter pipe in both materials are quite similar, whereas weld cost per mile of the 36 inch X70 pipe is slightly lower than that of the 24 inch X52 pipe.
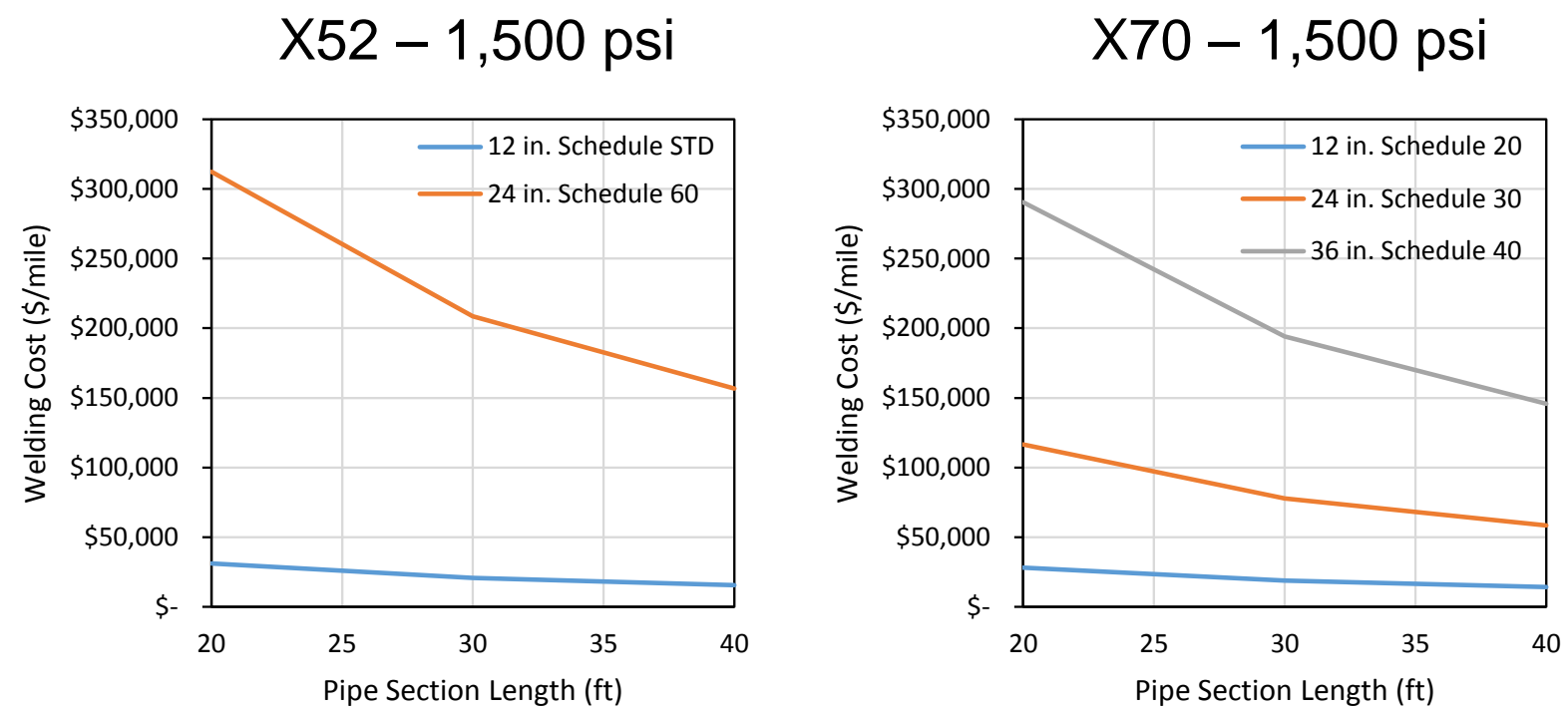

Figure A.3: Welding costs per mile as a function of pipe section length for two pipeline conditions.

We now assume a fixed length of $40 \mathrm{ft}$ to simplify calculations and allow for further comparison (Fig. I4). Figure A.3 (at $40 \mathrm{ft}$. pipe section length on horizontal axis) and Figure A.4 show a $10 \%$ reduction in welding cost in the X70 12 inch pipe material intended for 1500 psi (10.34 MPa) service due to its thinner wall ( $0.25 \mathrm{in.} X 70$ versus $0.375 \mathrm{in.} \mathrm{X52}$ ). The thinner wall for a given diameter reduces welding cost significantly as less weld metal deposition is required. The cost advantage of the higher strength pipe becomes much more pronounced when increasing the pipe diameter to $24 \mathrm{in}$. and $36 \mathrm{in}$. diameters. The 24 in. diameter X70 pipe has its welding cost reduced by over $60 \%$ as compared to the X52 24 in. diameter. Note that the 36 in. diameter X70 pipe has a lower per-mile welding cost than the 24 in. X52 pipe. 


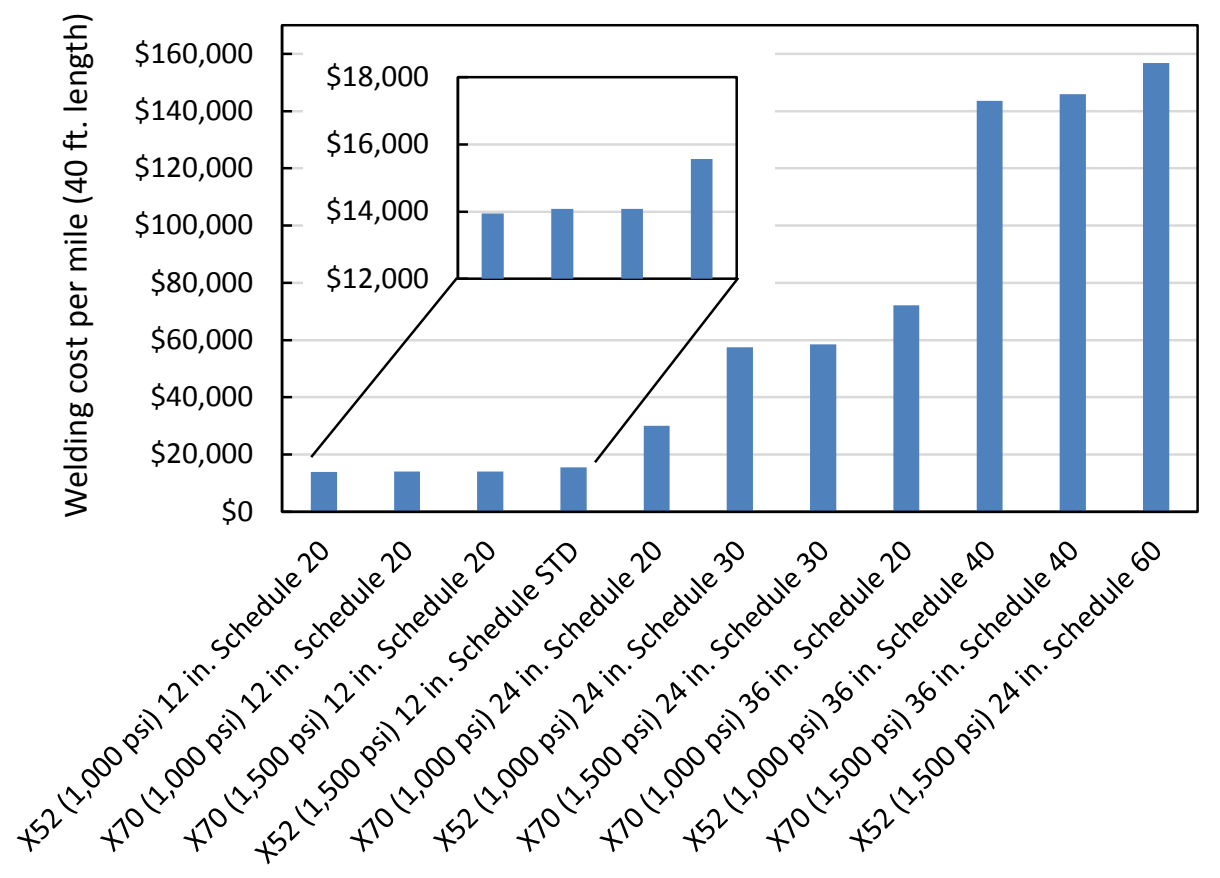

Figure A.4: Ranking of girth weld cost per mile for matrix of pipeline conditions (valid for $40 \mathrm{ft}$. pipe section length).

The variables shown in Table A.2 are subject to fluctuations and some of them have considerable variation that could strongly influence pipeline welding costs. A sensitivity analysis was performed to project the variation of inputs on welding costs per mile for $40 \mathrm{ft}$. pipe lengths. Table A.4 contains the upper and lower bounds of input variables for the sensitivity evaluation. The values shown represent ranges that the authors found throughout various sources as described in the model input section. For the sensitivity analysis, only one variable is adjusted to "low" and "high" conditions while the other values are left constant at the "nominal" value. Some variables are dependent on others (See Table A.2), however this analysis only considers first order effects. Note that deposition rate is a function of welding current and therefore current is the variable that was adjusted. The filler metal selection is dependent on pipe strength level. Power consumption (and cost) depends on the welding current and voltage and weld time.

Cost sensitivity to model input variation is shown in the "tornado" charts in Figure A.5 for two comparable cases. The first case illustrates potential cost variation in joining the X52 24 in. pipe for 1,000 psi service and the second case illustrates variation in joining the X70 24 in. pipe for 1,000 psi service. The baseline or mean joining cost of the former case is about $\$ 58 \mathrm{~K} / \mathrm{mile}$ and about $\$ 30 \mathrm{~K} / \mathrm{mile}$ for the latter case. When considering the possible input variations in Table A.4, the cost variability for each case becomes apparent as the impacted ranges are ranked highest to lowest. For both cases, the ranking was consistent. Changes in operator factor and welding current induce the highest cost variability, and power cost and welding voltage changes induce the lowest cost variability from the mean cost. Operator factor has a large cost penalty when welder productivity decreases to low percentages. Also, when lower welding currents are used (e.g., in a poorly designed weld procedure), a significant cost penalty occurs since filler metal deposition rate decreases. The overhead and labor rates 
have little variation by percentage among the two cases. Voltage, transfer efficiency, and power cost each influence the cost variation by $<1 \%$ of the mean cost.

It was noted above that welding costs do not vary significantly among the different strength pipe materials with a fixed diameter and thickness combination. The sensitivity analysis shows that the variation in weld filler metal cost between weld deposit strength levels are small compared to other costs. The filler metal cost influences cost to a small degree (variation is $<1.5 \%$ of mean cost).

Table A.4: Input values for sensitivity analysis.

\begin{tabular}{|l|c|c|c|}
\hline Consumable Costs & Low & High & Nominal \\
\hline E6010 Filler Cost $(\$ / \mathrm{lb})$ & 2.73 & 3.75 & 3.19 \\
\hline E8010 Filler Cost $(\mathbf{\$} / \mathrm{lb})$ & 3.20 & 4.41 & 3.89 \\
\hline Power Cost $(\mathbf{\$} / \mathrm{kWhr})$ & 0.1 & 0.3 & 0.15 \\
\hline Labor Costs & & & \\
\hline Labor Rate $(\mathbf{\$} / \mathrm{hr})$ & 18.19 & 33.19 & 23.19 \\
\hline Overhead Rate $(\mathbf{\$} / \mathrm{hr})$ & 18.19 & 33.19 & 23.19 \\
\hline Human Factors & & & \\
\hline Operator Factor $(\%)$ & 10 & 35 & 20 \\
\hline Welding Process & & & \\
\hline Average Current $(\mathrm{amps})$ & 100 & 250 & 180 \\
\hline Transfer Efficiency $(\%)$ & 65 & 75 & 70 \\
\hline Deposition Rate $(\mathrm{lb} / \mathrm{hr})$ & 1.8 & 5.8 & 3.9 \\
\hline
\end{tabular}

X52 (1,000 psi) 24 in. Schedule 30

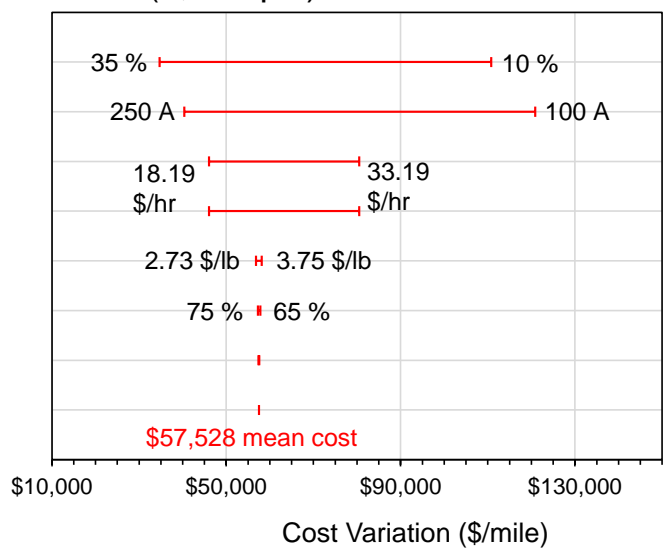

X70 (1,000 psi) 24 in. Schedule 20

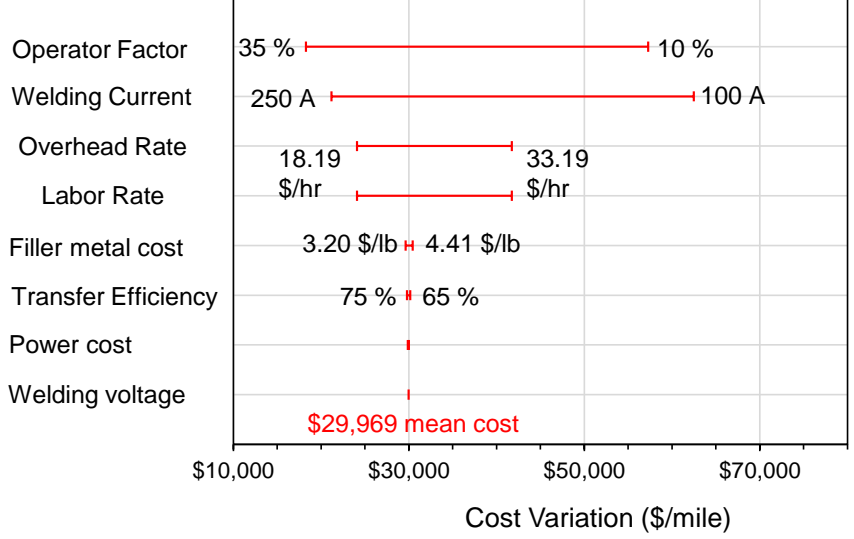

Figure A.5: Results of sensitivity analysis showing cost variations associated with welding cost input ranges.

The following can be concluded from the welding cost analysis:

- A cost model was used to compute welding costs for different grades, diameters, and schedules of pipelines revealing significant variation among the cases. The cost per mile of installing transmission piping varies by over an order of magnitude depending on pipe diameter and thickness. 
- Welding costs are dominated by labor and overhead (>90\%) and only a small fraction (< $7 \%)$ are capital costs for consumables including filler metal and power for welding.

- Significant savings are demonstrated in utilizing higher-strength pipe with reduced wall thickness since welding costs can be drastically reduced.

- The most impactful areas where savings can be realized during construction include implementing weld procedures with high deposition rates and employing more experienced welders that spend high fractions of their work shift performing welding.

APPENDIX B: SI Values For Tables (Appendix table number followed by table number in the main text)

Table B.1 - Table 2: Baseline (X52) Natural Gas Pipe Thickness Analysis (ASME B31.8-2012)

\begin{tabular}{|l|c|c|c|}
\hline \multirow{2}{*}{$\begin{array}{l}\text { Operating } \\
\text { Pressure }\end{array}$} & \multicolumn{3}{|c|}{ Pipe Diameter $(\mathrm{mm})$} \\
\cline { 2 - 4 } & 304.8 & 609.6 & 914.4 \\
\hline $6.89 \mathrm{MPa}$ & Required & Thickness- schedule $(\mathrm{mm})$ \\
\hline $10.34 \mathrm{MPa}$ & $20(6.35)$ & $20(9.53)$ & $20(12.70)$ \\
\hline
\end{tabular}

Table B.2 - Table 3: Baseline (X52) Hydrogen Gas Pipe Thickness Analysis (ASME B31.12-2008)

\begin{tabular}{|l|c|c|c|}
\hline \multirow{2}{*}{$\begin{array}{l}\text { Operating } \\
\text { Pressure }\end{array}$} & \multicolumn{3}{|c|}{ Pipe Diameter (mm) } \\
\cline { 2 - 4 } & 304.8 & 609.6 & 914.4 \\
\hline $6.89 \mathrm{MPa}$ & Required Thickness- schedule (inches) \\
\hline $10.34 \mathrm{MPa}$ & STD (6.35) & $30(14.275)$ & $40(19.05)$ \\
\hline
\end{tabular}

Table B.3 - Table 4: Hydrogen Gas Pipe Thickness Analysis for X70 (ASME B31.12-2008)

\begin{tabular}{|l|c|c|c|}
\hline \multirow{2}{*}{ Operating } & \multicolumn{3}{|c|}{ Pipe Diameter (mm) } \\
\cline { 2 - 4 } Pressure & 304.8 & 609.6 & 914.4 \\
\hline $6.89 \mathrm{MPa}$ & Required Thickness- schedule (inches) \\
\hline $10.34 \mathrm{MPa}$ & $40(8.382)$ & $30(14.275)$ & N/A \\
\hline
\end{tabular}

Table B.4 - Table 5: Hydrogen Gas Pipe Thickness Analysis for X70 (ASME B31.12-Proposed)

\begin{tabular}{|l|c|c|c|}
\hline \multirow{2}{*}{ Operating } & \multicolumn{3}{|c|}{ Pipe Diameter (mm) } \\
\cline { 2 - 4 } Pressure & 304.8 & 609.6 & 914.4 \\
\hline $6.89 \mathrm{MPa}$ & $20(6.350)$ & $20(9.525)$ & $20(7.925)$ \\
\hline $10.34 \mathrm{MPa}$ & $20(6.350)$ & $30(14.122)$ & $40(19.05)$ \\
\hline
\end{tabular}


Table B.5 - Table 6: Cost increase for X52 pipes engineered for hydrogen service (B31.12) relative to natural gas service (B31.8)

\begin{tabular}{|l|c|c|c|}
\hline \multirow{2}{*}{ Operating } & \multicolumn{3}{|c|}{ Pipe Diameter $(\mathrm{mm})$} \\
\cline { 2 - 4 } Pressure & 304.8 & 609.6 & 914.4 \\
\hline $6.89 \mathrm{MPa}$ & \multicolumn{3}{|c|}{ Total Cost Differential/Mile } \\
\hline $10.34 \mathrm{MPa}$ & $11 \%$ & $42 \%$ & $44 \%$ \\
\hline
\end{tabular}

Table B.6 - Table 7: Cost impact of increasing diameter and/or operating pressure of X52 pipe for hydrogen service (12", 1000 psi baseline)

\begin{tabular}{|l|c|c|c|}
\hline \multirow{2}{*}{ Operating } & \multicolumn{3}{|c|}{ Pipe Diameter $(\mathrm{mm})$} \\
\cline { 2 - 4 } Pressure & 304.8 & 609.6 & 914.4 \\
\hline $6.89 \mathrm{MPa}$ & \multicolumn{3}{|c|}{ Total Cost Differential/Mile } \\
\hline $10.34 \mathrm{MPa}$ & - & $214 \%$ & $540 \%$ \\
\hline
\end{tabular}

Table B.7 - Table 8: Cost impact of replacing X52 with X70 for hydrogen service - all other variables equal

\begin{tabular}{|l|c|c|c|}
\hline \multirow{2}{*}{$\begin{array}{l}\text { Operating } \\
\text { Pressure }\end{array}$} & \multicolumn{3}{|c|}{ Pipe Diameter $(\mathrm{mm})$} \\
\cline { 2 - 4 } & 304.8 & 609.6 & 914.4 \\
\hline $6.89 \mathrm{MPa}$ & $-2 \%$ & $-24 \%$ & $-25 \%$ \\
\hline $10.34 \mathrm{MPa}$ & $-19 \%$ & $-31 \%$ & $\mathrm{~N} / \mathrm{A}$ \\
\hline
\end{tabular}

\footnotetext{
1 “2012 Fuel Cell Technologies Market Report”, Office of Energy Efficiency and Renewable Energy, U. S. Department of Energy, DOE/EE-0973 (October 2013)

${ }^{2}$ Yang, C, Ogden, J. INTERNATIONAL JOURNAL OF HYDROGEN ENERGY, Volume: 32, Issue: 2, Pages: 268-286, DOI: 10.1016/j.ijhydene.2006.05.009, (Feb 2007)

${ }^{3}$ U. S. Energy Information Administration statistics

4 "The Impact of Increased Use of Hydrogen on Petroleum Consumption and Carbon Dioxide Emissions", U. S. Energy Information Administration (Sept. 2008)

${ }^{5}$ Michler, T; Naumann, J, Sattler, E; "Influence of high pressure hydrogen on S-N fatigue in two austenitic stainless steels", Int. J. Fatigue, 51, pp1-7, (2013)

${ }^{6}$ Stalheim DG, Barnes KR, McCutcheon DB; "Alloy designs for high strength oil and gas transmission linepine steels", Proc. Int. Symp. On Microalloyed Steels for the Oil and Gas Industry, Fazackerley WJ, Bordignon P, Hulka K, Siciliano F ed., pp. 73-107, TMS, (2007)

${ }^{7}$ Parker, N.; "Using Natural Gas Transmission Pipeline Costs to Estimate Hydrogen Pipeline Costs", Institute of Transportation Studies, University of California - Davis, available at http://escholarship.org/uc/item/9m40m75r (2004)

${ }^{8}$ Brown, D; Cabe, J; Stout, T; “National lab uses OGJ data to develop cost equations", Oil and Gas Journal, Jan. 3, 2011, pp. 108-112, (2011)

9 "H2A Delivery Components Model Version 1.1: Users Guide", (April 2006), available at http://www.hydrogen.energy.gov/h2a_delivery.html

${ }^{10}$ B31.12 - International Piping Code - Hydrogen Piping and Pipelines, American Society of Mechanical Engineers (2008)
} 
${ }^{11}$ Hayden, L; “Code for Hydrogen Pipelines”, Presentation to the DOE Hydrogen Pipeline Working Group Workshop, Augusta, GA (2005), available at http://www1.eere.energy.gov/hydrogenandfuelcells/pdfs/hpwgw_code_hayden.pdf

${ }^{12}$ San Marchi, C.; Somerday, BP; "Technical Reference for Hydrogen Compatibility of Materials", Sandia National Laboratory Report SAND2012-7321, (2012)

${ }^{13}$ Slifka, AS; Drexler, ES; Stalheim, DG; Amaro, RA; Lauria, DS; Stevenson, AE;Hayden, LE; "The Effect of Microstructure On The Hydrogen-Assisted Fatigue Of Pipeline Steels" Proc. ASME Pressure Vessels and Piping Conference, Paris, France; (2013)

${ }^{14}$ Amaro, RL; Rustagi N; Findley, KO; Drexler, ES; Slifka, AJ; “Modeling the fatigue crack growth of X100 pipeline steel in gaseous hydrogen", Int. J. Fatigue, 59, pp 262-271, (2014)

${ }^{15}$ Amaro R. L., Drexler, E. S., Rustagi, N., Nanninga, N. E., Levy, Y. S., Slifka, A. J.; “Fatigue crack growth of pipeline steels in gaseous hydrogen- predictive model calibrated to API-5L X52", Proc. 2012 International Hydrogen Conference, Sofronis P, Somerday, B. P., ed. , Jackson Lake WY, USA. (2012)

${ }^{16}$ B31.8 - International Piping Code - Gas Transmission and Distribution Piping Systems, American Society of Mechanical Engineers (2014)

${ }^{17}$ Briottet, L, Batisse, R, de Dinechin, G, Langlois, P, Thiers, L. INTERNATIONAL JOURNAL OF HYDROGEN ENERGY, Volume: 37, Issue: 11, Pages: 9423-9430, DOI: 10.1016/j.ijhydene.2012.02.009, Published: JUN 2012 